Review

\title{
What We Know and Still Need to Know about Gender Aspects of Delusional Disorder: A Narrative Review of Recent Work
}

\author{
Alexandre González-Rodríguez ${ }^{1,2,3, *}$, Marina Esteve ${ }^{1,2}$, Aida Álvarez ${ }^{1,2,3}$, \\ Armand Guardia $^{1,2}$, José Antonio Monreal ${ }^{1,2,3,4}$, Diego Palao ${ }^{1,2,3,4}$, \\ Javier Labad ${ }^{1,2,3,4}$ \\ 1 Department of Mental Health, Parc Taulí Un iversity Hospital, Sabadell, \\ Barcelona, 08208, Spain \\ 2 Institut d'Investigació i Innovació Parc Taulí (I3PT), Sabadell, Barcelona, 08208, \\ Spain \\ 3 Department of Psychiatry and Forensic Medicine, Autonomous University of \\ Barcelona (UAB), Cerdanyola del Vallès, Barcelona, 08193, Spain \\ 4 Centro de Investigación Biomédica en Red de Salud Mental (CIBERSAM), \\ Madrid, 208029, Spain \\ * Correspondence: Alexandre González-Rodríguez, Email: agonzalezro@tauli.cat.
}

\section{G Open Access}

Received: 21 March 2019

Accepted: 06 May 2019

Published: 09 May 2019

Copyright (C) 2019 by the author(s). Licensee Hapres, London, United Kingdom. This is an open access article distributed under the terms and conditions of Creative Commons Attribution 4.0 International License.

\section{ABSTRACT}

While gender differences in the psychopathology and clinical course of schizophrenia have been extensively reported, the potential for analogous differences in delusional disorder has been understudied. Our aim in this paper is to focus on the recent literature on delusional disorder and to explore gender aspects. This is a non-systematic, narrative and critical review. The review is divided into the following main sections: gender differences in epidemiology, symptomatology, phenotypic factor analyses, psychiatric comorbidity, response and adherence to medications, and clinical trajectories. Culture-bound delusional syndromes are also addressed, and potential causes for gender differences and their treatment are critically discussed. Although DMS-5 reports no gender differences in the frequency of delusional disorder or in delusional content, several studies have found erotomania to be more frequent in women. There seem also to be gender differences in affective and substance abuse comorbidity, which may prove clinically important. The loss of the neuroprotection conferred by estrogens during the reproductive period in women may trigger depressive symptoms after menopause. The interaction of age and gender has been insufficiently studied as is also the case for selective cultural pressures on men and women and their impact on the content of delusions. Studies designed to focus on gender differences in response to treatment are currently needed in delusional disorder.

KEYWORDS: delusional disorder; paranoia; psychosis; women; gender; culture-bound syndromes 


\section{INTRODUCTION}

The present Diagnostic and Statistical Manual of Mental Disorders, Fifth Edition (DSM-5) [1] has defined delusional disorder (DD) as the presence of one or more delusions lasting one month or longer in the absence of affective symptoms, prominent hallucinations, or other psychotic symptoms. Relatively little research has focused specifically on DD until recently [2].

Although epidemiological research is sparse, the population prevalence of DD is estimated to be approximately $0.2 \%$ [1], with an incidence of 0.7 to 3.0 per 100,000 , a lower frequency, therefore, than that of other psychoses (e.g., schizophrenia and bipolar disorder) [3,4]. Subtypes of DD have been grouped according to delusional theme. Accordingly, DSM-5 categorizes seven subtypes [1]. Comorbid conditions have also been identified, depression being the most common $[5,6]$.

The pathogenesis of DD remains speculative. Sensory impairment (e.g., vision and hearing loss), as well as social isolation, stand out as risk factors for DD [7]. As is the case for other psychoses, research has implicated genes, neurochemistry, and brain structure as potentially causative. A recent example of progress in this area is the finding by Vicens et al. [8] of abnormalities in the medial frontal, anterior cingulate cortex and insula in DD, which specifically implicates these brain regions in pathogenesis.

Dopamine and serotonin transmission has been found critical to antipsychotic response in general, and this has been found to apply to DD [9]. To further the understanding of neurochemistry in DD, the authors proposed the simultaneous investigation of genetics and neuroimaging.

Many of the delusions of DD are also found in schizophrenia where gender differences have been reported in age at onset, treatment response and clinical course [10], and attributed the estrogen protection hypothesis [11,12]. Evidence supporting this hypothesis derives from several sources-epidemiological and clinical.

Epidemiological research has shown that schizophrenia onset in women is later than in men and that women have a second peak of incidence at the end of the reproductive years. Clinically, gender differences have been found in treatment response in schizophrenia in favor of women [13,14]. Older women, however, show a decline in antipsychotic response at menopause and beyond [15]. Few studies have explored gender differences in DD.

The aim of this review, therefore, is to integrate relatively current gender-specific research in DD: epidemiological findings, psychopathological symptoms, phenotypic factor analyses, psychiatric comorbidities, responsiveness and adherence to antipsychotics, and to explore gender aspects of culture-bound delusional syndromes. Potential explanations for the presence or lack of gender differences will be critically discussed. 


\section{METHODS}

We searched the Google Scholar and Pubmed databases for English language papers published since 2000 that referred to gender in the context of delusional disorder (DD). Abstracts were excluded. Our team scanned abstracts of several thousand titles, most of which were excluded because they addressed delusions in the context of schizophrenia. We selected 80 articles that were relevant to our aim. Where many papers referred to the same earlier work, that earlier publication was also included. We then carried out what became a nonsystematic, narrative and critical review based on most of the papers we found; some were omitted because they repeated material cited earlier.

This review is divided into the following main sections: (1) gender differences in epidemiological aspects and male/female prevalence of DD, (2) gender differences in psychopathological symptoms, (3) gender differences in phenotypic factor analyses (e.g., paranoid, cognitive, affective, schizoid), (4) gender differences in psychiatric comorbidity, (5) gender differences in antipsychotic response and adherence to medications and (6) gender differences in diagnostic stability and clinical trajectories of DD. In a further step, culture-bound delusional syndromes were reviewed using a gender lens. Finally, potential explanations for gender differences were addressed and critically discussed.

\section{RESULTS}

\section{Gender Differences in the Epidemiology of Delusional Disorder}

Delusional disorder (DD) has been traditionally perceived by many psychiatrists as a difficult-to-treat and treatment-resistant disorder. Its prevalence has been found to be low compared to schizophrenia and other related disorders [3]. The estimated prevalence and incidence varies depending on the characteristics of the sample [2,16]. For instance, some studies have explored the epidemiology of DD in the community [17], others have recruited their samples from inpatient settings, or even prisons [16]. Furthermore, depending on the mean age of the sample, prevalence and incidence may differ, as DD has been found most frequently in middle and old age populations [3].

DSM-5 reports that lifetime prevalence of DD is estimated to be around $0.2 \%$ [1]. Crowe and co-workers found the prevalence of DD to be between 24 to 30 per 100,000 and the annual incidence to be 0.7 to 3.0 per 100,000 [18]. Smith and Buckley [19], who found a prevalence of $0.03 \%$, describe DD as uncommon.

Some epidemiological research has focused on older populations. A notable study is the MRC-ALPHA study by Copeland and co-workers-a cohort study of an age- and gender-stratified sample of 5222 community residents from Liverpool aged 65 years and over. DSM-III-TR criteria were applied for the diagnosis of both schizophrenia and DD [17]. The prevalence of DD was found to be $0.04 \%$. The annual incidence was 15.6 
per 100,000. The prevalence of DD has been found to be higher in forensic samples. Sampling inmates from a prison, Tamburello and colleagues, for instance, estimated a prevalence of $0.24 \%$, which is eight times higher than found in community samples [16].

Gender differences in the epidemiology of DD have been subject to some debate and controversy [20]. For instance, DSM-5 reports no major gender differences [1], but this most probably depends on study design and methodology. At older ages, several studies have found DD to be more frequent in women [21]. A recent large sample study from a tertiary care center in India, however, was unable to replicate this finding [22]. In an inpatient study, part of the larger HALLES study, Wustmann and co-workers were also unable to find gender differences that were statistically significant [23]. Interestingly, Bleuler reported that men were more likely than women to present with DD [20]. Depending on how the diagnosis of DD is ascertained, co-morbidity with substance abuse will skew the demographics towards male prevalence. Delusions can be hidden from view but substance use, which is disinhibiting, will cause delusional acting out, thus bringing the individual to the attention of clinicians or to law enforcement. Differences between men and women in comorbidities is presented later in this review.

\section{Gender Differences in Psychopathological Symptoms}

DSM-5 classifies delusional disorder (DD) into seven subtypes according to the content of delusions [1]. These categories are: delusions of persecution, erotomania, grandiosity, jealousy, somatic delusions, mixed and unspecified subtypes.

Despite the scarcity of research in this area, it is well-established that the persecutory subtype is the most common, followed by jealous, somatic or erotomanic, varying with the study and the setting [24]. Prevalence rates of subtypes vary considerably. While several studies report that the persecutory type is present in around $49 \%$ of DD patients $[23,25]$, more recent studies have found still higher rates, particularly in inpatient samples [21,24].

Most previous studies show no gender differences in delusions of persecution, whereas gender differences in favor of men have been found for grandiose and jealous subtypes and in favor of women for erotomania [21,24]. In contrast with these findings, as part of the HALLES study, Wustmann and colleagues found no statistically significant differences in the content of delusions between men and women with DD, suggesting that other variables, such as acting on one's delusions, may influence clinical expression [23]. Substance abuse, depression, and age may explain some of the inconsistencies.

Age is important. González-Rodríguez and colleagues were interested in the role of menopause. They asked whether DD women with premenopausal onset differed in sociodemographic and clinical features from those with postmenopausal onset $(n=80)$ [26]. They found that the 
erotomanic subtype was more frequent in women with premenopausal onset, whereas postmenopausal women more commonly suffered from jealous and somatic subtypes of DD. These findings suggest that menopausal status is an important variable. Mild hallucinatory phenomena in DD (e.g., olfactory and tactile), not prominent enough to consider a change of diagnosis, have been found, especially in later life, more commonly in women than in men $[11,26]$.

\section{Gender Differences in Phenotypic Factorial Analyses}

In recent years, several investigators have studied clinical phenotypes in patients with DD. The root question is whether DD is, in fact, a distinct nosological entity or whether it is a subtype of schizophrenia or, alternately, related to mood disorders [3].

With these questions in mind, Serretti and co-workers analyzed the structure of all psychopathological symptoms in a sample of 108 inpatients with DD [27]. This research group used the Operational Criteria (OPCRIT) checklist and identified four independent factors: depressive symptoms, hallucinations, delusions and irritability symptoms, suggesting that DD is a heterogeneous disorder with different clinical profiles. The delusion factor explained a high percentage of the variance of the model used, whereas depressive symptoms, hallucinations and irritability explained less of the variance. Addressing the same questions, de Portugal and colleagues explored psychopathological factors in a sample of 86 outpatients assessed using the Positive and Negative Syndrome Scale (PANSS) [28]. They identified four consistent factors explaining almost 59\% of the variance of the total model (e.g., paranoid, cognitive, schizoid and affective), each factor being associated with specific clinical features. For instance, the paranoid dimension was correlated with a relatively poor response and poor adherence to psychotropic medications; the cognitive dimension was associated with non-prominent hallucinations; the schizoid dimension was linked to dysthymic symptoms, and the affective dimension was associated with somatic delusions and an increased risk of suicide. No statistically significant differences with respect to gender were reported, not for content of delusions, and not for the phenotypic expression of symptoms.

\section{Gender Differences in Psychiatric Co-morbidity}

Patients with DD frequently suffer from comorbidities, mainly mood disorders and especially depressive disorders. Although exact rates are not available, the prevalence of comorbid mood disorder is estimated to be between $21 \%$ and $58 \%$ [6].

With respect to other comorbid axis I disorders, Maina and co-workers reported that $3.1 \%$ of DD outpatients in their series had at least one comorbid anxiety disorder [29]. Wustmann and colleagues report that the majority of their DD patients (55.8\%) had depressive symptoms that did not achieve the level needed to diagnose affective 
disorder. Moreover, $16.3 \%$ of their patients experienced anxiety, which, once again, did not fulfil diagnostic criteria [23].

Román Avezuela et al. found that women with DD were more likely than men to report comorbid depressive disorders, and that women's depressions were more severe than those of men [24,30]. This finding is not entirely consistent with the 2011 study by Wustmann and co-workers [31] who found that, although more women than men manifested depressive episodes during the course of DD (37.5\% vs. 17.6\%), the difference was not statistically significant. Other authors also found no statistically significant gender differences in either the presence or the severity of depression in patients with DD [32].

In the González-Rodríguez et al. pre and post menopausal onset study, women whose DD started prior to menopause showed a higher level of depressive symptoms and a tendency toward higher rates of psychotic relapse than those with post menopausal onset [26].

We were unable to find relevant data on the prevalence of substance use disorders in association with DD. However, there are well-known gender differences (male > female) in the premorbid consumption of substances [32-35]. Roman Avezuela and co-workers found a statistically significant difference between men and women in the presence of a history of active substance use one month prior to DD onset $(40.9 \%$ vs. $3.6 \%$ [24]. They found greater male prevalence of both cannabis abuse/dependence ( $22.7 \%$ vs. $0 \%$ ) and alcohol (22.7\% vs. $3.6 \%)$ [24]. The gender difference in comorbid substance use is important with respect to safety concerns because, acting on delusional beliefs, men are more likely than women to commit acts of violence [36].

The main characteristics of the studies mentioned above can be found in Table 1.

\section{Gender Differences in Response and Adherence to Antipsychotics}

The main treatment for DD is antipsychotic medication in combination with supportive therapy and attention to comorbidities and issues of safety. Leucht et al. recently pointed out the lack of consensus in the definition of antipsychotic response when it came to patients with schizophrenia [37]. Few studies have used specific scale-derived cut-off points to analyze response rates and most have only reported mean score changes from the baseline to endpoint $[38,39]$. The same is true for antipsychotic response in DD patients. A recent study concluded that the best approach was to use PANNS or Brief Psychiatric Rating Scale (BPRS)derived cut-offs, in combination with scores on the Clinical Global Impression (CGI) scale [40]. Because of the lack of consensus in the definition of treatment response, the current opinion that DD is a treatment-resistant disorder can be neither confirmed nor refuted [41]. 
Table 1. Psychiatric co-morbidity in patients with delusional disorder and distribution by gender.

\begin{tabular}{|c|c|c|c|c|}
\hline \multirow[b]{2}{*}{$\begin{array}{l}\text { Author and year } \\
\text { of publication }\end{array}$} & \multirow[b]{2}{*}{ Sample $(n)$} & \multicolumn{2}{|c|}{ Psychiatry co-morbidity, $n$ (\%) } & \multirow[b]{2}{*}{$\begin{array}{l}\text { Psychiatry co- } \\
\text { morbidity by gender, } \\
n(\%)\end{array}$} \\
\hline & & $\begin{array}{l}\text { Affective } \\
\text { co-morbidity, } n \text { (\%) }\end{array}$ & $\begin{array}{l}\text { Substance use } \\
\text { disorders } \\
\text { co-morbidity, } \\
n(\%)\end{array}$ & \\
\hline $\begin{array}{l}\text { Román Avezuela } \\
\text { et al., } 2015 \text { [24] }\end{array}$ & $\begin{array}{l}50 \text { ( } 28 \text { women } \\
\text { and } 22 \text { men) }\end{array}$ & $\begin{array}{l}\text { Depressive disorder: } \\
24 \%\end{array}$ & $\begin{array}{l}\text { THC: } 10 \% \\
\text { Alcohol: } 12 \%\end{array}$ & $\begin{array}{l}\text { Substance use } \\
\text { Women: 3.6\% (THC } \\
\text { 0\%; Alcohol 3.6\%) } \\
\text { Men: 40.9\% (THC } \\
\text { 22.7\%; Alcohol 22.7\%) } \\
\text { Depressive disorder } \\
\text { Women: 35.7\% } \\
\text { Men: } 9.1 \%\end{array}$ \\
\hline $\begin{array}{l}\text { Wustmann et al., } \\
2011 \text { [31] }\end{array}$ & $\begin{array}{l}43 \text { ( } 21 \text { women } \\
\text { and } 22 \text { men) }\end{array}$ & $\begin{array}{l}\text { Depressive symptoms: } \\
55.8 \%\end{array}$ & Alcohol: $6.06 \%$ & $\begin{array}{l}\text { Depressive symptoms } \\
\text { Women: } 57.1 \% \\
\text { Men: } 54.5 \% \\
\text { Alcohol dependency } \\
\text { Women: } 6.3 \% \\
\text { Men: } 5.9 \%\end{array}$ \\
\hline $\begin{array}{l}\text { de Portugal et al., } \\
2010 \text { [32] }\end{array}$ & $\begin{array}{l}86 \text { ( } 53 \text { women, } \\
33 \text { men) }\end{array}$ & $\begin{array}{l}\text { Depressive symptoms: } \\
43.6 \%\end{array}$ & $\begin{array}{l}\text { Substance abuse: } \\
17.62 \%\end{array}$ & $\begin{array}{l}\text { Depressive symptoms: } \\
\text { Women: } 47.7 \% \\
\text { Men: } 50 \% \\
\text { Substance abuse: } \\
\text { Women: } 11.3 \% \\
\text { Men: } 30.3 \%\end{array}$ \\
\hline $\begin{array}{l}\text { Maina et al., } 2001 \\
\text { [29] }\end{array}$ & $\begin{array}{l}64 \text { ( } 42 \text { women } \\
\text { and } 22 \text { men) }\end{array}$ & $\begin{array}{l}\text { Affective symptoms: } \\
53.1 \%\end{array}$ & $4.7 \%$ & $\begin{array}{l}\text { Affective symptoms: } \\
\text { Women: } 69.6 \% \\
\text { Men: } 30.4 \% \\
\end{array}$ \\
\hline $\begin{array}{l}\text { Marino et al., } 1993 \\
\text { [30] }\end{array}$ & $\begin{array}{l}67 \text { ( } 44 \text { women } \\
\text { and } 23 \text { men) }\end{array}$ & $\begin{array}{l}\text { Depressive disorder: } \\
50.7 \%\end{array}$ & - & - \\
\hline $\begin{array}{l}\text { Rudden et al., } \\
1983 \text { [35] }\end{array}$ & $\begin{array}{l}88 \text { ( } 44 \text { women } \\
\text { and } 44 \text { men) }\end{array}$ & $\begin{array}{l}\text { Major affective } \\
\text { disorder: } 16 \%\end{array}$ & - & $\begin{array}{l}\text { Major affective } \\
\text { disorder: } \\
\text { Women: } 15.9 \% \\
\text { Men: } 18.18 \%\end{array}$ \\
\hline
\end{tabular}

Abbreviations: THC, Cannabis.

Medication adherence has been judged to be poor in DD [42]. A systematic review was conducted to determine the methods currently used to evaluate adherence in this population [43]. The investigators found that studies assessing adherence by objective methods (antipsychotic plasma concentrations for example) showed higher rates of adherence than those using more subjective methods (such as review of medical records). With respect to gender differences in adherence, 
there is little consistency in the psychosis literature as to whether men or women are more or less likely to take their antipsychotics as prescribed although a study from the US that used an electronic adherence monitor showed a better adherence to AP in women than men after hospital discharge for a psychotic illness [44]. With respect to DD, Wustmann et al. also found women to be much more compliant than men to treatment; they were more likely than men to be prescribed psychopharmacological medication and, in general, they had higher rates of receipt of healthcare service than men [31].

Roman-Avezuela et al. did not find any gender differences in DD in the response to antipsychotic treatment nor in symptom remission at the time of hospital discharge [24]. This is in contrast with the findings of Wustman and co-workers, who observed that women more frequently than men continue to show chronic symptoms of DD even after treatment. DD remained unremitted in $81.3 \%$ of women versus $47.1 \%$ of men [31].

To the best of our knowledge, no studies have investigated gender differences in DD in treatment response to comorbid depression or anxiety, comorbid substance abuse, nor in issues of treatment alliance or prevention of violence. Such work remains to be done.

\section{Gender Differences in Diagnostic Stability and Clinical Trajectories of Delusional Disorder}

DD shows remarkable diagnostic stability over time [21,45,46]. Studies focusing on stability in DD has used sample sizes ranging from 9 to 163 patients and have included follow-up periods of up to 20 years. The diagnostic stability of DD has been reported as being between $64 \%$ and $94 \%$ [47-49]. When the diagnosis is changed to another category of disorder, it is usually changed to schizophrenia (3-28\%) or affective illness (3-8\%) [50].

Marneros and co-workers found diagnostic stability to be $78.8 \%$ in a recent study, with an only $21.2 \%$ shift to a different psychiatric disorder [45]. Researchers examining gender differences in diagnostic stability have concluded that the proportion of patients usually retaining the DD diagnosis is greater in women than in men $[21,24,45]$.

In the Wustmann et al. study ( 21 women and 22 men), the men tended more frequently than the women to have their diagnosis changed to schizophrenia or schizoaffective disorder [31]. Kulkarni and colleagues [22] found similar results. They retrospectively reviewed case records of 455 patients with persistent DD (236 males (51.9\%) and 219 females (48.1\%)). Over the follow-up period, $92.4 \%$ of women and $85.3 \%$ of men showed diagnostic stability.

The association of DD with subsequent dementia is worth noting. Almeida et al. conducted a prospective study of 37,770 men with DD and reported that 8068 (21.4\%) developed dementia [51]. Older men with a DD diagnosis had a nearly three times greater risk of developing dementia than age peers without DD. Korner et al. also found an increase 
in the later prevalence of dementia in DD [52]. They compared a total of 1437 patients with DD with 7302 patients with osteoarthritis. Patients with DD had an 8 times increased rate of subsequent dementia compared with osteoarthritis patients. Finally, Leinonen et al. reported that, in a sample of 18 patients with established DD, 5 (28\%) developed dementia before death [53]. This is approximately double the expected incidence in the general population of the same age. A comparison with schizophrenia patients was not done but would have been relevant to assess the contribution of antipsychotic medication to this association.

The main results of the studies referred to above are presented in Table 2 .

\section{Culture-Bound Delusional Syndromes and Gender Differences}

It is generally accepted that the cultural and historical framework of each society determines what constitutes a delusion. Sometimes, beliefs labelled as delusional in one environment can be commonplace in other cultures, belief in ghosts or witchcraft for instance. The social consequences, the conformity with generally held beliefs, and the tolerance of the local society, help clinicians to differentiate what is diagnosed as a delusional disorder (DD). There are some delusional beliefs and consequent behaviors that are confined to specific societies and are referred to as culture-bound syndromes. We describe six of the more frequent such syndromes, some of which are much more frequent in one gender than the other [54].

Lycanthropy, the belief that a person can be transformed into an animal and, therefore, must behave like one [55] stems from old European folklore and still persists in some parts of Europe. It has been frequently related to psychotic depression and preoccupation with guilt and punishment. The religion, culture and environment of the patient determines the animal of choice, who usually represents the forces of evil [56]. To the best of our knowledge, no gender differences have been described in this syndrome.

Dhat syndrome is an excessive concern with the loss of a vital fluid called "dhat", without which a person becomes debilitated [57]. This syndrome is found in India where it is quite prevalent. The perception is that a white secretion (usually thought of as semen) is being lost through the urine [54,57]. In western classification systems, such a belief might be called somatization or hypochondriasis. The syndrome is usually associated with men although rare cases in women have been reported, in which case the symptoms are attributed to the loss of vital vaginal fluid. 
Table 2. Representative studies investigating diagnostic stability and clinical trajectories in delusional disorder and data by gender.

\begin{tabular}{|c|c|c|c|c|c|c|}
\hline $\begin{array}{l}\text { Author \& year } \\
\text { of publication }\end{array}$ & $\begin{array}{l}\text { Sample Study } \\
\text { (DD) }\end{array}$ & $\begin{array}{l}\text { Time of } \\
\text { follow-up } \\
\text { (years) }\end{array}$ & $\begin{array}{l}\text { Diagnostic } \\
\text { stability, overall } \\
\text { sample (DD) }\end{array}$ & $\begin{array}{l}\text { Conversion to other } \\
\text { diagnoses, overall sample } \\
\text { (switch) }\end{array}$ & $\begin{array}{l}\text { Diagnostic stability } \\
\text { by gender (DD) }\end{array}$ & $\begin{array}{l}\text { Conversion to other } \\
\text { diagnoses by gender } \\
\text { (switch) }\end{array}$ \\
\hline $\begin{array}{l}\text { Leinonen et al., } \\
\text { (2004) [53] }\end{array}$ & $\begin{array}{l}N=18 \\
(\mathrm{~W}: 16, \mathrm{M}: 2)\end{array}$ & 10 years & $\begin{array}{l}\text { DD: } 18(100 \%) \\
\text { 13/18 died during } \\
\text { de follow-up }\end{array}$ & Dementia: 5 (28\%) & Not specified & Not specified \\
\hline $\begin{array}{l}\text { Korner et al., } \\
(2008)[52]\end{array}$ & $\begin{array}{l}N=1437 \\
\text { patients with DD } \\
\text { W: } 1115(77.6 \%) ; \\
\text { M: } 322(22.4 \%)\end{array}$ & 8 years & Not specified & $\begin{array}{l}\text { Dementia: } 218 \text { (15.2\%), } \\
\text { RR } 3.15 \text { (95\% CI 1.93-5.14), } \\
\text { adjusted for age and } \\
\text { calendar year }\end{array}$ & Not specified & Not specified \\
\hline $\begin{array}{l}\text { Wustmann et al., } \\
\text { (2011) [31] }\end{array}$ & $\begin{array}{l}N=33 \\
(\mathrm{~W}: 21, \mathrm{M}: 22)\end{array}$ & 10.8 years & DD: $21(63.6 \%)$ & $\begin{array}{l}\text { SZ: } 6(18.2 \%) \\
\text { SZA: } 1(3 \%) \\
\text { Remitted: } 5(15.1 \%)\end{array}$ & $\begin{array}{l}\text { Woman (DD): } 13 \\
(81.3 \%) \\
\text { Men (DD): } 8(47.1 \%)\end{array}$ & $\begin{array}{l}\text { SZ: Women: } 1(3 \%) \text {, } \\
\text { Men: } 5 \text { (15.1\%) } \\
\text { SZA: Women: 0, Men: } 1 \\
(3 \%)\end{array}$ \\
\hline $\begin{array}{l}\text { Kulkarni et al., } \\
2017 \text { [22] }\end{array}$ & $\begin{array}{l}N=455 \\
(\mathrm{~W}: 219, \mathrm{M}: 236)\end{array}$ & $\begin{array}{l}\text { Retrospective } \\
\text { review } \\
\text { published } \\
\text { earlier till } 455 \\
\text { cases } \\
\text { (not specified) }\end{array}$ & DD: 403 (88.6\%) & $\begin{array}{l}\text { SZ: Not specified } \\
\text { BD: Not specified } \\
\text { MDD: Not specified }\end{array}$ & $\begin{array}{l}\text { Women (DD): } 92.4 \% \\
\text { Men (DD): } 85.3 \%\end{array}$ & Not specified \\
\hline $\begin{array}{l}\text { Almeida et al., } \\
\text { (2019) [51] }\end{array}$ & $\begin{array}{l}N=37770 \\
\text { Men with } \\
\text { psychotic disorder } \\
\text { (included DD) }\end{array}$ & 17.7 years & Not specified & $\begin{array}{l}\text { Dementia: } 8068 \text { (21.4\%) } \\
\text { and } 23999(63.5 \%) \text { died } \\
\text { during follow up }\end{array}$ & Not specified & Not specified \\
\hline
\end{tabular}

Abbreviations: BD, Bipolar Disorder; DD, Delusional Disorder; M, Men; MDD, Major Depressive Disorder; SZ, Schizophrenia; SZA, Schizoaffective; W, Women. 
Koro is the belief that the genitals (usually the penis) have been retracted into the abdomen. The fear is that they will disappear and that death will be imminent [58]. The syndrome has been linked to Asian and African cultures, but has more recently also been described in Europe and America [59]. It is characteristic of subcultures where reproductive capacity is particularly important. Primary and secondary forms of koro have been described, the first related to anxiety and the second to depression and psychosis [59]. Koro is much more prevalent in men than in women but a few rare female cases (retraction of uterus or breasts) have been described.

Couvade syndrome is by definition a male syndrome-the sensation by a male that he is first pregnant, then experiences labour and then suffers from postpartum depression. It is considered a sympathy syndrome, an overidentification with a female partner [60] and is characterized by symptoms of anxiety and depression [61]. Women who are not pregnant can sometimes overidentify with a pregnant woman to whom they feel close. This is related to the more common syndrome of pseudocyesis or delusional pregnancy in women. The psychological roots of that syndrome, however, are based not in identification but in either the intense wish or the intense fear of being pregnant [62].

Ekbom syndrome or delusional parasitosis is the belief that one is infected by varieties of minute organisms [63]. Sufferers often provide "proof of infestation" by bringing their care providers real insects ("match box sing") that they found on their bodies. This syndrome is seen in many parts of the world although the identity of the infective organism will differ with geographic region. The false belief can start with a real infestation, can be believed to be "caught" from another person, usually an enemy, and has sometimes been associated with dementia [64,65]. The syndrome can be classified as a primary delusional disorder or as secondary to an anxiety or depressive disorder. Regarding gender, most of papers report a 2/3 ratio favouring women. In women, the symptoms also last longer than they do in men.

Going amok is a culture-bound syndrome of men in Malaysia and Indonesia preceded by a belief that they are disrespected by their community [66]. Typically, a generally mild mannered man rushes into a crowded public area with a weapon and attacks whomever he meets. Bystanders intervene and the perpetrator may be killed or may commit suicide. Amok is thought to be a form of suicide with honour in cultures where suicide, especially in men, is heavily stigmatized. If the perpetrator is not killed, he loses consciousness and, on recovery, claims amnesia for the incident, which, restores his honour and establishes him as a man that has to be feared.

The main characteristics of these syndromes can be found in Table 3. 
Table 3. Main characteristics of culture bound delusional syndromes and gender differences.

\begin{tabular}{|c|c|c|c|c|}
\hline Syndrome & Populations & Diagnosis (DSM-5) & Gender & Treatment \\
\hline $\begin{array}{l}\text { Lycanthropy } \\
{[55,56]}\end{array}$ & $\begin{array}{l}\text { Christians, Jews in } \\
\text { Europe and } \\
\text { America }\end{array}$ & $\begin{array}{l}\text { Psychotic disorder } \\
\text { Depressive disorders }\end{array}$ & No differences & $\mathrm{AD} \pm \mathrm{AP}$ \\
\hline Dhat [57] & India, Asia & $\begin{array}{l}\text { Depressive disorders } \\
\text { Anxiety } \\
\text { Somatization disorders }\end{array}$ & $\begin{array}{l}\text { Male (semen) }>\text { female } \\
\text { (vaginal discharge) }\end{array}$ & $\begin{array}{l}\text { Anxiolytics } \\
\text { AD }\end{array}$ \\
\hline Koro $[58,59]$ & Asia, Africa & Panic attack & $\begin{array}{l}\text { Male (penis) > female } \\
\text { (vulva/chest) }\end{array}$ & $\begin{array}{l}\text { Anxiolytics } \\
\text { AD }\end{array}$ \\
\hline Couvade [60] & $\begin{array}{l}\text { Africa, Europe, } \\
\text { Asia, and many } \\
\text { indigenous groups } \\
\text { in the Americas }\end{array}$ & $\begin{array}{l}\text { Mood disorders } \\
\text { Anxiety } \\
\text { Somatization disorders }\end{array}$ & Male & $\begin{array}{l}\mathrm{AD} \pm \mathrm{AP} \\
\text { Anxiolytics }\end{array}$ \\
\hline Ekbom [65] & Around the world & $\begin{array}{l}\text { Delusional disorder } \\
\text { Depressive and anxiety } \\
\text { disorders }\end{array}$ & $\begin{array}{l}\text { Female (longer } \\
\text { duration) } \\
>\text { Male }\end{array}$ & $\begin{array}{l}\mathrm{AP} \\
\mathrm{AD}\end{array}$ \\
\hline Amok [66] & $\begin{array}{l}\text { Malaysia, } \\
\text { Indonesia }\end{array}$ & Form of suicide & Male> Female & - \\
\hline
\end{tabular}

Abbreviations: $\mathrm{AD}$, antidepressants; $\mathrm{AP}$, antipsychotics.

Interestingly, many culture-bound syndromes show definite gender differences in their expression which appear to be determined by the specific roles assigned to men and women in different cultures. Although it is difficult to consider manifestations of psychological issues in one's own culture as being culture bound syndromes, repeated plastic surgery syndromes and anorexia nervosa (both associated with women), can probably be placed in this category. There is recognized pressure on women in the West to be thin, which has made women-specific eating disorders a favorite flashpoint of discussion as to their status as Western culture bound syndromes [67-69]. Bulimia nervosa [68] perhaps more than other disorders fits the definition, but this is controversial. Problem gamblers and anabolic steroid users on the other hand have been also considered as representing culture bound syndromes [70,71], and they are likely to be men.

Although there are no randomized controlled studies, what this suggests is that Western mores put pressure on women to be beautiful and on men to be strong and wealthy, and that such cultural pressures manifest in gender-specific psychopathological ways, both in belief and in behavior. Such pressures can also determine age differences in sickness behavior [67,68]. For instance, women in their reproduct course, speculations, but understanding age and gender psychological and cultural factors may lead to more effective interventions for delusional disorders. 


\section{CONCLUSIONS AND FUTURE DIRECTIONS}

The lifetime prevalence of delusional disorder (DD) has been estimated to be $0.2 \%$ and the annual incidence is reported as 15.6 cases per 100,000 people in community-based studies [1]. Epidemiological studies addressing gender differences often do not agree with each other, perhaps because age and menopausal status have not been taken into account. Symptoms may also vary with age. Postmenopausal women with DD and all DD patients in later life are more likely than younger patients to present with non-prominent hallucinatory phenomena. This may be a function of cognitive changes related to age or to endocrine changes [2]. The differences in delusional themes may also be shaped by brain changes related to hormones and age and to psychological factors.

Several research groups have tried to delineate and differentiate clinical subtypes found in DD populations [27,28]; a few gender differences have been found among the subtypes. Some gender differences in comorbidity have also been suggested; in women, comorbid psychotic and depressive symptoms after menopause can be attributed to the loss of estrogen [72,73]. Very few studies have investigated gender differences in treatment response in DD populations, although response to antipsychotics appears to be roughly similar in men and women [24]. Treatment adherence would need to be taken into account, as well as patient age and type of antipsychotic used before true gender differences in treatment response could be confirmed or refuted.

To sum up, there are several aspects of gender and DD that need further study. First of all, gender differences in global epidemiological findings should be further investigated. The prevalence of DD (and its subtypes) seems to differ according to age and reproductive status and culture. Postmenopausal women lose the neuroprotection conferred by estrogens, and the occurrence of DD may, thus, become more frequent in women as compared to men at this age. Gender differences in clinical aspects or subtypes of DD also need further investigation. A genderspecific approach to treatment needs to address drug adherence and drug response, and especially comorbidities. Women with DD suffer more depressive symptoms as they age, and by implication, effective treatment of these symptoms will positively impact the clinical course and prognosis of DD. Cognitive decline after menopause in women stands out as a risk factor for hallucinatory phenomena which may benefit from cognitive enhancers. Future studies need to consider gender-specific treatment not only for depression and cognition but also to pay attention to male/female selective cultural pressures and their influence on the content of delusions. Substance abuse, particularly in men, needs urgent treatment in order to prevent incidents of violence originating in specific delusions. Delusional disorders increase in frequency with age and, as the population ages, it is important to focus research on this understudied set of conditions. 


\section{AUTHORS CONTRIBUTIONS}

AGR was involved in the electronic search and selection of papers and wrote the first draft of the manuscript. ME, AA and AG supported data and collaborated in the first draft of the manuscript. JAM and DP critically revised the manuscript. JL revised the paper and supervised all the review.

\section{CONFLICTS OF INTEREST}

JL has received honoraria for lectures or advisory board membership from Janssen, Otsuka, Lundbeck and Angelini. AGR has received honoraria or paid for travels from Janssen, Pfizer, Lundbeck and Ferrer.

\section{FUNDING SOURCES}

This research did not receive any specific grant from funding agencies in the public, commercial, or not-for-profit sectors.

\section{ACKNOWLEDGMENTS}

Javier Labad received an Intensification of the Research Activity Grant (SLT006/17/00012) from the Health Department of the Generalitat de Catalunya.

\section{REFERENCES}

1. American Psychiatric Association. Diagnostic and Statistical Manual of Mental Disorders (DSM-5). 5th ed. Arlington (US): American Psychiatric Association; 2013.

2. Kendler KS. The clinical features of paranoia in the 20th century and their representation in diagnostic criteria from DSM-III through DSM-5. Schizophr Bull. 2017;43(2):332-43. doi: 10.1093/schbul/sbw161

3. Kendler KS. Demography of paranoid psychosis (delusional disorder): a review and comparison with schizophrenia and affective illness. Arch Gen Psychiatry. 1982;39(8):890-902.

4. Manschreck TC, Khan NL. Recent advances in the treatment of delusional disorder. Can J Psychiatry. 2006;51(2):114-9.

5. de Portugal E, Martínez C, González N, del Amo V, Haro JM, Cervilla JA. Clinical and cognitive correlates of psychiatric comorbidity in delusional disorder outpatients. Aust N Z J Psychiatry. 2011;45(5):416-25. doi: 10.3109/00048674.2010.551279

6. González-Rodríguez A, Molina-Andreu O, Navarro Odriozola V, Gastó Ferrer C, Penadés R, Catalán R. Delusional disorder: An overview of depressive symptoms and antidepressant use. Eur J Psychiatry. 2013;27(4):265-76.

7. Porras Segovia A, Guerrero Jiménez M, Carrillo de Albornoz C, Cervilla Ballesteros J. Comorbidity between delusional disorder and sensory deficits. 
Results from the deliranda case register. Eur Psychiatry. 2016;33(Suppl):S144-5.

8. Vicens V, Radua J, Salvador R, Anguera-Camós M, Canales-Rodríguez EJ, Sarró S, et al. Structural and functional brain changes in delusional disorder. Br J Psychiatry. 2016;208(2):153-9. doi: 10.1192/bjp.bp.114.159087

9. González-Rodríguez A, Estrada F, Montalvo I, Monreal JA, Palao D, Labad J. F229. The biological underpinnings of treatment response in delusional disorder: a systematic review of qualitative evidence-to-date. Schizophr Bull. 2018;44(Suppl 1):S311.

10. Riecher-Rössler A. Oestrogens, prolactin, hypothalamic-pituitary-gonadal axis, and schizophrenic psychoses. Lancet Psychiatry. 2017;4(1):63-72. doi: 10.1016/S2215-0366(16)30379-0

11. Seeman MV. Treating schizophrenia at the time of menopause. Maturitas. 2012;72(2):117-20. doi: 10.1016/j.maturitas.2012.03.008

12. Riecher-Rössler A, Kulkarni J. Estrogens and gonadal function in schizophrenia and related psychoses. Curr Top Behav Neurosci. 2011;8: 155-71. doi: 10.1007/7854_2010_100

13. Usall J, Suarez D, Haro JM, SOHO Study Group. Gender differences in response to antipsychotic treatment in outpatients with schizophrenia. Psychiatry Res. 2007;153(3):225-31.

14. Ochoa S, Usall J, Cobo J, Labad X, Kulkarni J. Gender differences in schizophrenia and first-episode psychosis: a comprehensive literature review. Schizophr Res Treatment. 2012;2012:916198. doi: 10.1155/2012/916198

15. González-Rodríguez A, Catalán R, Penadés R, Ruiz Cortés V, Torra M, Seeman MV, Bernardo M. Antipsychotic Response Worsens With Postmenopausal Duration in Women With Schizophrenia. J Clin Psychopharmacol. 2016;36(6):580-7.

16. Tamburello AC, Bajgier J, Reeves R. The prevalence of delusional disorder in prison. J Am Acad Psychiatry Law. 2015;43(1):82-6.

17. Copeland JR, Dewey ME, Scott A, Gilmore C, Larkin BA, Cleave N, et al. Schizophrenia and delusional disorder in older age: community prevalence, incidence, comorbidity, and outcome. Schizophr Bull. 1998;24(1):153-61.

18. Crowe RR, Roy MA. Delusional disorders. In: Fatemi SH, Clayton PJ, editors. The medical basis of psychiatry. 3rd ed. Totowa (US): Humana Press; 2008. p. 125-31.

19. Smith DA, Buckley PF. Pharmacotherapy of delusional disorders in the context of offending and the potential for compulsory treatment. Behav Sci Law. 2006;24(3):351-67.

20. Bleuler E. Lehrbuch der Psychiatrie. Berlin (Germany): Springer-Verlag; 1983.

21. González-Rodríguez A, Molina-Andreu O, Imaz Gurrutxaga ML, Catalán Campos R, Arroyo MB. A descriptive retrospective study of the treatment and outpatient service use in a clinical group of delusional disorder patients. Rev Psiquiatr Salud Ment. 2014;7(2):64-71. doi: 10.1016/j.rpsm.2013.01.004 
22. Kulkarni KR, Arasappa R, Prasad MK, Zutshi A, Chand PK, Murthy P, et al. Gender differences in persistent delusional disorder. Indian J Psychol Med. 2017;39:216-7.

23. Wustmann T, Pillmann F, Friedemann J, Piro J, Schmeil A, Marneros A. The clinical and sociodemographic profile of persistent delusional disorder. Psychopathology. 2012;45(3):200-2. doi: 10.1159/000332004

24. Román Avezuela N, Esteve Díaz N, Domarco Manrique L, Domínguez Longás A, Miguélez Fernández C, de Portugal E. Gender differences in delusional disorder. Rev Asoc Esp Neuropsiq. 2015;35(125):37-51. doi: 10.4321/ S0211-57352015000100004

25. de Portugal E, González N, Haro JM, Autonell J, Cervilla JA. A descriptive case-register study of delusional disorder. Eur Psychiatry. 2008;23(2):125-33.

26. González-Rodríguez A, Molina-Andreu O, Penadés R, Garriga M, Pons A, Catalán R, et al. Delusional Disorder over the Reproductive Life Span: The Potential Influence of Menopause on the Clinical Course. Schizophr Res Treatment. 2015;2015:979605. doi: 10.1155/2015/979605

27. Serretti A, Lattuada E, Cusin C, Smeraldi E. Factor analysis of delusional disorder symptomatology. Compr Psychiatry. 1999;40(2):143-7.

28. de Portugal E, González N, del Amo V, Haro JM, Díaz-Caneja CM, Luna del Castillo Jde D, et al. Empirical redefinition of delusional disorder and its phenomenology: the DELIREMP study. Compr Psychiatry. 2013;54(3):243-55. doi: 10.1016/j.comppsych.2012.08.002

29. Maina G, Albert U, Badà A, Bogetto F. Occurrence and clinical correlates of psychiatric co-morbidity in delusional disorder. Eur Psychiatry. 2001;16(4):222-8.

30. Marino C, Nobile M, Bellodi L, Smeraldi E. Delusional disorder and mood disorder: can they coexist? Psychopathology. 1993;26(2):53-61.

31. Wustmann T, Pillmann F, Marneros A. Gender-related features of persistent delusional disorders. Eur Arch Psychiatry Clin Neurosci. 2011;261(1):29-36. doi: 10.1007/s00406-010-0130-1

32. de Portugal E, González N, Miriam V, Haro JM, Usall J, Cervilla JA. Gender differences in delusional disorder: Evidence from an outpatient sample. Psychiatry Res. 2010;177(1-2):235-9. doi: 10.1016/j.psychres.2010.02.017

33. Munro A, Mok H. An overview of treatment in paranoia/delusional disorder. Can J Psychiatry. 1995;40(10):616-22.

34. Galderisi S, Bucci P, Üçok A, Peuskens J. No gender differences in social outcome in patients suffering from schizophrenia. Eur Psychiatry. 2012;27(6):406-8. doi: 10.1016/j.eurpsy.2011.01.011

35. Rudden M, Sweeney J, Frances A, Gilmore M. A comparison of delusional disorders in women and men. Am J Psychiatry. 1983;140(12):1575-8.

36. Beck JC. Delusions, substance abuse, and serious violence. J Am Acad Psychiatry Law. 2004;32(2):169-72.

37. Leucht S, Davis JM, Engel RR, Kane JM, Wagenpfeil S. Defining 'response' in antipsychotic drug trials: recommendations for the use of scale-derived cutoffs. Neuropsychopharmacology. 2007;32(9):1903-10. 
38. Leucht S, Davis JM, Engel RR, Kissling W, Kane JM. Definitions of response and remission in schizophrenia: recommendations for their use and their presentation. Acta Psychiatr Scand Suppl. 2009;(438):7-14. doi: 10.1111/j.1600-0447.2008.01308.x

39. Leucht S. Measurements of response, remission, and recovery in schizophrenia and examples for their clinical application. J Clin Psychiatry. 2014;75(Suppl 1):8-14. doi: 10.4088/JCP.13049su1c.02

40. González-Rodríguez A, Estrada F, Monreal JA, Palao D, Labad J. A systematic review of the operational definitions for antipsychotic response in delusional disorder. Int Clin Psychopharmacol. 2018;33(5):261-7. doi: 10.1097/YIC.0000000000000227

41. Muñoz-Negro JE, Cervilla JA. A systematic review on the pharmacological treatment of delusional disorder. J Clin Psychopharmacol. 2016 Dec;36(6):684-90.

42. Grover S, Biswas P, Avasthi A. Delusional disorder: Study from North India. Psychiatry Clin Neurosci. 2007;61(5):462-70.

43. González-Rodríguez A, Estrada F, Monreal JA, Palao D, Labad J. A systematic review of methods for the measurement of antipsychotic adherence in delusional disorder. J Clin Psychopharmacol. 2018;38(4):412-4. doi: 10.1097/JCP.0000000000000893

44. Diaz E, Neuse E, Sullivan MC, Pearsall HR, Woods SW. Adherence to conventional and atypical antipsychotics after hospital discharge. J Clin Psychiatry. 2004;65(3):354-60. doi: 10.4088/JCP.v65n0311

45. Marneros A, Pillmann F, Wustmann, T. Delusional disorders. Are they simply paranoid schizophrenia. Schizophr Bull. 2012;38(3):561-8. doi: 10.1093/schbul/ sbq125

46. Fusar-Poli P, Cappucciati M, Rutigliano G, Hesliln M, Stahl D, Brittenden Z, et al. Diagnostic stability of ICD/DSM First Episode Psychosis diagnoses: Metaanalysis. Schizophr Bull. 2016;42(6):1395-406. doi: 10.1093/schbul/sbw020

47. Opjordsmoen S. Long-term course and outcome in delusional disorder. Acta Psychiatr Scand. 1988;78:576-86.

48. Haahr U, Friis S, Larsen TK, Melle I, Johannessen JO, Opjordsmoen S, et al. First-episode psychosis: diagnostic stability over one and two years. Psychopathology. 2008;41:322-9.

49. Opjordsmoen S. Delusional disorder as a partial psychosis. Schizophr Bull. 2014;40(2):244-7. doi: 10.1093/schbul/sbt203

50. Grover S, Gupta N, Kumar Mattoo, S. Delusional disorders: An overview. German J Psychiatry. 2006;9:62-73.

51. Almeida OP, Ford AH, Hankey GJ, Yeap BB, Golledge J, Flicker L. Risk of dementia associated with psychotic disorders in later life: the health in men study (HIMS). Psychol Med. 2019;49(2):232-42. doi: 10.1017/S003329171800065X

52. Kørner A, Lopez AG, Lauritzen L, Andersen PK, Kessing LV. Delusional disorder in old age and the risk of developing dementia: a nationwide register-based study. Aging Ment Health. 2008;12(5):625-9. doi: $10.1080 / 13607860802343118$ 
53. Leinonen E, Santala M, Hyötylä T, Santala H, Eskola MNSc N, Salokangas RK. Elderly patients with major depressive disorder and delusional disorder are at increased risk of subsequent dementia. Nord J Psychiatry. 2004;58(2):161-4.

54. Chadda RK. Dhat syndrome: is it a distinct clinical entity? A study of illness behaviour characteristics. Acta Psychiatr Scand. 1995;91(2):136-9.

55. Bou Khalil R, Dahdah P, Richa S, Kahn DA. Lycanthropy as a culture-bound syndrome: a case report and review of the literature. J Psychiatr Pract. 2012;18(1):51-4. doi: 10.1097/01.pra.0000410988.38723.a3

56. Rojo Moreno J, Rojo Moreno M, Valdemoro García C, Rojo Sierra M. The delusion of lycanthropic transformation. Actas Luso Esp Neurol Psiquiatr Cienc Afines. 1990;18(5):327-31.

57. Prakash S, Sharan P, Sood M. A qualitative study on psychopathology of dhat syndrome in men: Implications for classification of disorders. Asian J Psychiatr. 2018;35:79-88. doi: 10.1016/j.ajp.2018.05.007

58. Garg K, Kumar CN, Sharadhi C. Koro: Much more than just a culture bound syndrome. Asian J Psychiatr. 2017;29:146-7. doi: 10.1016/j.ajp.2017.05.022

59. Dan A, Mondal T, Chakraborty K, Chaudhuri A, Biswas A. Clinical course and treatment outcome of Koro: A follow up study from a Koro epidemic reported from West Bengal, India. Asian J Psychiatr. 2017;26:14-20. doi: 10.1016/j.ajp.2016.12.016

60. Thippaiah SM, George V, Birur B, Pandurangi A. A case of concomitant pseudocyesis and Couvade syndrome variant. Psychopharmacol Bull. 2018;48(3):29-32.

61. Mrayan L, Abujilban S, Abuidhail J, Bani Yassein M, Al-Modallal H. Couvade syndrome among Jordanian expectant fathers. Am J Mens Health. 2019;13(1):1557988318810243. doi: 10.1177/1557988318810243

62. Seeman MV. Pseudocyesis, delusional pregnancy, and psychosis: The birth of a delusion. World J Clin Cases. 2014;2(8):338-44. doi: 10.12998/wjcc.v2.i8.328

63. Bewley AP, Lepping P, Freudenmann RW, Taylor R. Delusional parasitosis: time to call it delusional infestation. Br J Dermatol. 2010;163(1):1-2. doi: 10.1111/j.1365-2133.2010.09841.x

64. Healy R, Taylor R, Dhoat S, Leschynska E, Bewley AP. Management of patients with delusional parasitosis in a joint dermatology/ liaison psychiatry clinic. Br J Dermatol. 2009;161(1):197-9. doi: 10.1111/j.1365-2133.2009.09183.x

65. Campbell EH, Elston DM, Hawthorne JD, Beckert DR. Diagnosis and management of delusional parasitosis. J Am Acad Dermatol. 2018;80(5): 1428-34. doi: 10.1016/j.jaad.2018.12.012

66. Imai H, Ogawa Y, Okumiya K, Matsubayashi K. Amok: a mirror of time and people. A historical review of literature. Hist Psychiatry. 2019;30(1):38-57. doi: 10.1177/0957154X18803499

67. Swartz L. Anorexia nervosa as a culture-bound syndrome. Soc Sci Med. 1985;20(7):725-30.

68. Keel PK, Klump KL. Are eating disorders culture-bound syndromes? Implications for conceptualizing their etiology. Psychol Bull. 2003;129(5):747-69.

69. Johnson TM. Premenstrual syndrome as a western culture-specific disorder. Cult Med Psychiatry. 1987;11(3):337-56. 
70. Ibáñez A, Blanco C, Moreryra P, Sáiz-Ruiz J. Gender differences in pathological gambling. J Clin Psychiatry. 2003;64(3):295-301.

71. Pope HG, Khalsa JH, Bhasin S. Body Image Disorders and Abuse of AnabolicAndrogenic Steroids Among Men. JAMA. 2017;317(1):23-4. doi: 10.1001/jama.2016.17441

72. González-Rodríguez A, Seeman MV. Pharmacotherapy for schizophrenia in postmenopausal women. Expert Opin Pharmacother. 2018;19(8):809-21. doi: 10.1080/14656566.2018.1465563

73. Seeman MV. Women who suffer from schizophrenia: Critical issues. World J Psychiatry. 2018;8(5):125-36. doi: 10.5498/wjp.v8.i5.125

How to cite this article:

González-Rodríguez A, Esteve M, Álvarez A, Guardia A, Monreal JA, Palao D, Labad J. What We Know and Still Need to Know about Gender Aspects of Delusional Disorder: A Narrative Review of Recent Work. J Psychiatry Brain Sci. 2019;4:e190009. https://doi.org/10.20900/jpbs.20190009 